\title{
Estimation of the Solid Waste Generation and Recycling Potential of the Hotel Sector: A Case Study in Hue City, Vietnam
}

\author{
Le Hoang Son ${ }^{1,2}$, Yasuhiro Matsui ${ }^{*}$, Do Thi Thu Trang ${ }^{3}$, Nguyen Phuc Thanh ${ }^{4}$ \\ ${ }^{1}$ Graduate School of Environmental and Life Science, Okayama University, Okayama, Japan \\ ${ }^{2}$ Danang University of Science and Technology, University of Da Nang, Da Nang, Vietnam \\ ${ }^{3}$ New Royal Village B202, 1497-1 Muramatsu, Tokai Village, Naka-gun, Ibaraki, 319-1112, Japan \\ ${ }^{4}$ Hitachi Zosen Corporation, Tokyo, Japan \\ Email: *matsui@okayama-u.ac.jp
}

How to cite this paper: Son, L.H., Matsui, Y., Trangm D.T.T. and Thanh, N.P. (2018) Estimation of the Solid Waste Generation and Recycling Potential of the Hotel Sector: A Case Study in Hue City, Vietnam. Journal of Environmental Protection, 9, 751-769.

https://doi.org/10.4236/jep.2018.97047

Received: April 17, 2018

Accepted: June 18, 2018

Published: June 21, 2018

Copyright $\odot 2018$ by authors and Scientific Research Publishing Inc. This work is licensed under the Creative Commons Attribution International License (CC BY 4.0).

http://creativecommons.org/licenses/by/4.0/

\begin{abstract}
This study examined the solid waste generation and recycling potential of the hotel sector in Hue City, Vietnam. The authors conducted waste measurement, waste composition, and questionnaire surveys for 45 target hotels over ten consecutive days. The waste generation rates (WGRs) by rooms, beds, guests, and workers were assessed by hotel class using the following three waste categories, considering informal waste collection: general waste (GW), separated recyclables (SRe), and separated food residue (SFR). The 5-star hotels exhibited the highest WGR per room at $1.61 \mathrm{~kg} / \mathrm{room} /$ day, while 1 -star hotels exhibited the lowest per-room WGR $(0.39 \mathrm{~kg} / \mathrm{room} /$ day $)$. Spearman Rank correlation test revealed that hotel class and per-room, per-bed, and per-guest WGRs were significantly positively correlated $(\mathrm{p}<0.01)$. The major components of $\mathrm{GW}$ were food waste $(40.9 \%$ to $57.4 \%)$, paper $(10.1 \%$ to $20.3 \%$ ), and plastic (10.7\% to $15.5 \%$ ). The recycling and composting potentials remaining in the GW were $19.3 \%$ to $38.5 \%$ and $38.0 \%$ to $57.9 \%$, respectively. Based on the WGRs and waste composition determined in this study, the estimated total amount of waste generated was 6.88 tons/day (6.26 to 7.62 tons/day, 95\% CI), of which $4.37(64 \%), 2.13(31 \%)$, and 0.38 tons/day (6\%) were GW, SFR, and SRe, respectively. The recycling and composting potentials remaining in GW were $0.94(13 \%)$ and 2.57 tons/day (37\%), respectively. High-class hotels should be considered as the highest priority targets for a "reduce, reuse, recycle" (3R) promotion campaign in the future, with estimated recycling and composting potentials of $0.27(4 \%)$ and 1.10 tons/day
\end{abstract}


(16\%), respectively.

\section{Keywords}

Waste Generation, Recycling Potential, Hotel Sector, Confidence Interval

Estimation

\section{Introduction}

Rapid urbanization, economic growth, and changing lifestyles have drastically increased the amount and variety of municipal solid waste (MSW) in developing countries [1]. Over 15 million tons of MSW are collected and treated annually by Vietnam's formal sector, of which $71 \%$ is directly filled in land [2]. Sanitary problems affecting public health and ecosystems have become an emerging environmental issue for Vietnamese authorities [3] [4] [5]. Furthermore, according to Vietnam's national strategy on the management of waste and discarded material issued in 2015 (Decree no. 38/2015/NĐ-CP), domestic solid waste must be classified and stored according to the following three groups: biodegradable organics, reusable and recyclables, and other wastes [6]. Currently, there are few official waste separation practices in Vietnam, and recycling activities are mainly conducted by the informal sector, for example, food waste collection by livestock breeders or recyclable material collection by waste pickers and junk-buyers [7] [8] [9].

Municipalities in Vietnam need to establish a MSW management system that considers public health, the efficient use of organic and recyclable waste, and recycling activities by the informal sector. Williams (2005) suggested that accurate data concerning estimated present and future production and composition of different types of waste were essential for efficient and economical long-term waste management planning [10]. It is important to understand the amount of waste generated; the waste composition, including the recycling potential of organic and recyclable materials; the waste stream, including informal sectors; and the contribution by each source as a scientific basis to establish a MSW management system and advance towards a sustainable society [11] [12].

The hotel sector is a primary source of MSW [9] [13] [14] [15] [16], and a major contributor of organic/wet waste in landfills, which is a major source of greenhouse gas emissions [17]. Otoma et al. (2013) suggested that the hotel sector contributed $9 \%$ of the total municipal solid waste in Danang, Vietnam [3].

Several studies have reported on the solid waste generation by Vietnam's hotel sector, and two approaches have been adopted for estimating waste quantity and composition. One distributes a questionnaire survey to the waste generators, and the other directly measures waste at the point at which it is generated or at the treatment facility [18]. Following the questionnaire survey method, Trung and Kumar (2005) surveyed 37 hotels in nine major Vietnamese tourist provinces, and reported the waste generation rate (WGR) per guest for different hotel classes in different areas [19]. However, the data regarding the amount of waste 
obtained by the questionnaire survey were not validated by comparing them with actual WGRs obtained by direct measurement. Following the direct measurement method, Byer et al. (2006) surveyed three hotels in Halong, Vietnam for one week, including 2-, 3-, and 4-star hotels. They measured WGRs per room and guest, and determined the physical composition of waste based on nine categories that included organic, inorganic, and recyclable waste [9]. Giang et al. (2017) surveyed nine hotels in Hoi An, Vietnam, and reported a per-room WGR that ranged from $0.35 \mathrm{~kg} / \mathrm{room} /$ day for a small hotel to $4 \mathrm{~kg} / \mathrm{room} /$ day for a 4-star hotel [20]. Otoma et al. (2013) surveyed 10 hotels in Danang, Vietnam, and reported average WGRs of $89.72 \mathrm{~kg} /$ hotel/day and $0.95 \mathrm{~kg} / \mathrm{room} /$ day [3]. However, these studies did not consider the influence factor of waste generation by the hotel sector, or the amounts of recyclable material and food residue collected by the informal sector.

Hue City is a major tourism city in Vietnam and houses a UNESCO World Heritage Site, the Complex of Hue Monuments, inscribed in 1993. The authors selected Hue City as a study area to determine waste generation by the hotel sector. To provide scientific information for promoting the 3Rs (reduce, reuse, recycle) in the hotel sector, this study aims to determine the WGRs of hotel sector in Hue City by 3 categories: compostable, recyclable, and other materials; identify the factors influencing WGRs; and describe the waste flow in detail. To consider the amount of waste collected by the informal sector and determine differences between hotel classes, the authors determined the amount of waste, including recyclables and food residues, collected by the informal sector and surveyed 45 accommodation facilities covering all hotel classes. This study also presents an interval estimation of the total amount of waste and its' components by Monte Carlo simulation. Uncertainty analysis was also conducted to understand the impact of the reliability of each waste flow component on the confidence interval of the total amount of waste.

\section{Methodology}

\subsection{Research Area and the Target Sample}

Hue City, the capital city of Thua Thien Hue Province located in central Vietnam, was selected as the study area (Figure 1). Hue City contains 27 wards with 354,124 people at a population density of 4779 persons per $\mathrm{km}^{2}$ as of 2015 [21]. In 2014, the Vietnamese government approved "Decision No. 649/QD-TTg-Approval for Adjustments to General Planning for Hue City to 2030 and a Vision to 2050", which called for Hue City to become environmentally sustainable [22]. Approximately 210 tons/day of waste is collected in Hue City and the general collection rates for the whole city and urban areas are approximately 89 and $90 \%$ - 95\%, respectively [23].

As a city with a UNESCO World Heritage Site, the number of tourists visiting Hue City rapidly increased at an annual growth rate of $10 \%$, reaching 2.5 million in 2012. To fulfill the demands of the visitors, the number of accommodation 


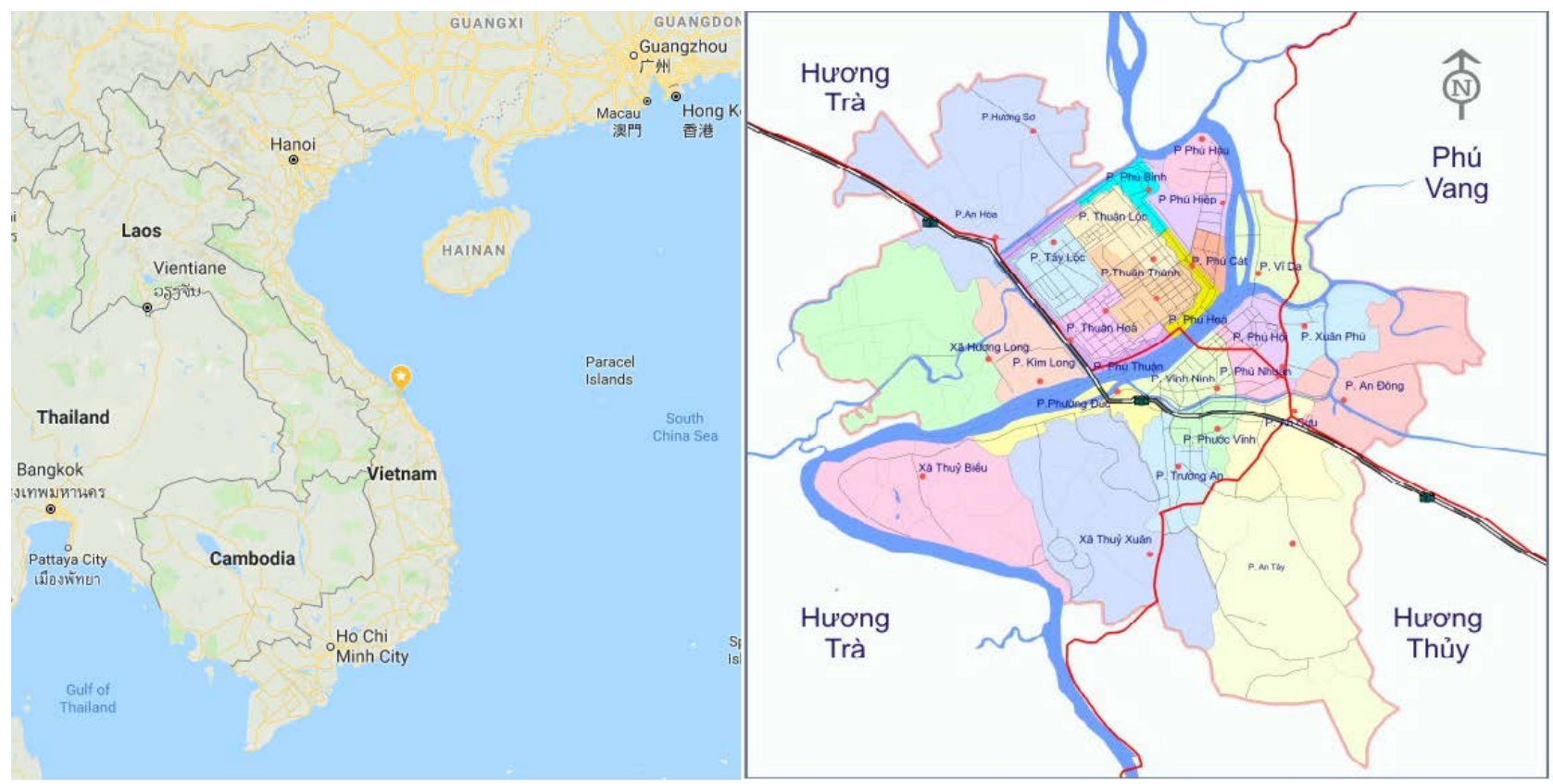

Figure 1. Location and boundary of the research area. Source: Google Maps and Hue's People Committee website.

facilities also continually increased, reaching 402 facilities with 7762 rooms and 13,660 beds in 2012 [24]. Based on the guest house and hotel classification standards, the 402 facilities in Hue City are categorized into six classes: guest house (GH), 1-star hotel, 2-star hotel, 3-star hotel, 4-star hotel, and 5-star hotel [25] [26].

To acquire representative samples of the hotel sector, the authors applied systematic sampling based on lists of hotels sorted by the number of beds. The lists were prepared separately for the abovementioned six classes, and the number of samples by hotel class is shown in Table 1 .

\subsection{Outline of Survey}

The survey procedure followed the methodology presented by Matsui et al. (2015) [13]. The authors conducted three surveys for all target samples from June 2 nd to 11th, 2012: actual waste measurement, waste composition and questionnaire surveys.

The authors requested the target facilities to keep their waste into the following three categories based on their typical separation manner:

- Separated recyclables (SRe): waste items separately kept for recycling, selling to the informal sector, or transferred to somewhere/someone else by the owners;

- Separated food residue (SFR): edible leftover food separately kept for feeding, collected by livestock breeders;

- General waste (GW): all remaining waste items collected daily by the formal waste collection sector, the Hue Urban Environment and Public Works State Company (HEPCO). 
Table 1. Numbers of hotels in Hue City and target samples by hotel class.

\begin{tabular}{ccccc}
\hline Hotel class & Facility & Room & Bed & Target sample \\
\hline Guest house & 289 & 2511 & 4071 & 10 \\
1-star hotel & 55 & 1071 & 2008 & 10 \\
2-star hotel & 31 & 1156 & 2226 & 7 \\
3-star hotel & 12 & 868 & 1615 & 7 \\
4-star hotel & 11 & 1509 & 2750 & 3 \\
5-star hotel & 4 & 648 & 990 & 45 \\
Total & 402 & 7763 & 13,660 & \\
\hline
\end{tabular}

Source: General statistics office, 2015.

The authors assessed the waste separation rate at the target facilities based on their usual separation behavior, which was categorized into the following four patterns: 1) recyclables and food residue separation, 2) recyclables separation only, 3) food residue separation only, and 4) no separation.

Regarding the actual waste measurement survey, the surveyors daily visited all the target facilities and directly measured the amount of waste generated over 10 consecutive days. The first three days were spent preparing the surveyors and target facilities, and data from the following seven days were used for the analysis.

The waste composition survey was conducted to evaluate the recycling and composting potentials of GW. The authors selected 21 target facilities with recyclables and food residue separation. (The sample size by hotel class is shown in Table 6) GW was classified based on materials (plastic, paper, kitchen waste, rubber and leather, grass, textile, metal, glass, ceramic, and miscellaneous), types (container/packaging, product, and other), and their potentials for recycling and composting. The authors sorted GW into 10 physical categories and 77 detailed sub-categories as shown in Table 2, and regrouped GW into the following three sub-categories:

- Recycling potential (Re): the recyclable portion of the discharged GW, defined based on Hue City's current informal sector trading market in 2012;

- Composting potential (Co): the compostable portion of the discharged GW, referred from the acceptable items established by Vietnamese composting facilities;

- Non-recyclable (NRe): The remaining portions of GW after the abovementioned recycling and composting potentials were considered.

The authors also conducted a questionnaire survey at the target facilities. The attributes and influencing factors on waste generation and recycling activities were collected and used for further analytical procedures.

\subsection{Analytical Procedure}

The WGRs were calculated by dividing the daily amount of waste generation by four business scale indicators: number of rooms, number of beds, number of 
Table 2. Categorization of waste from hotel sector.

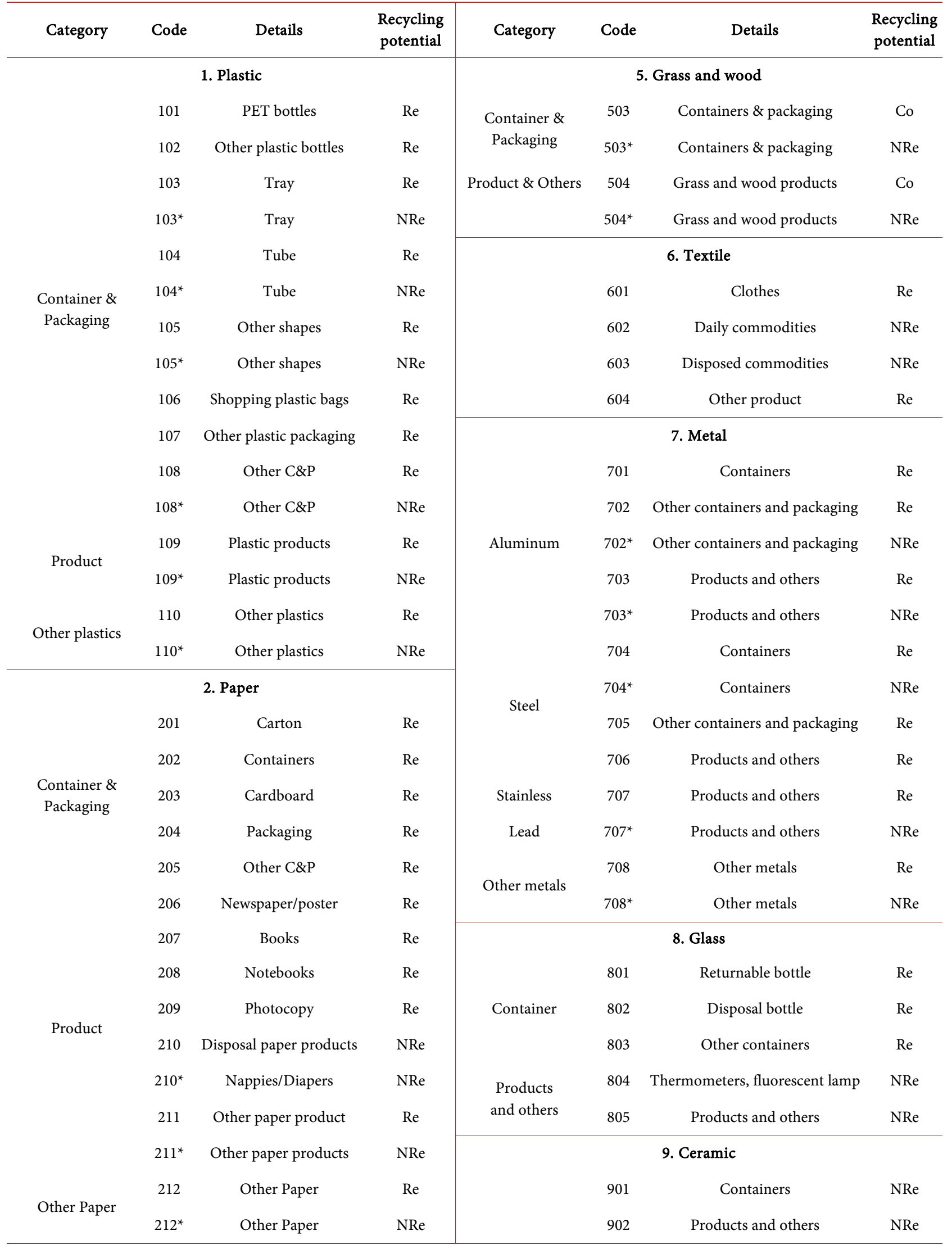




\section{Continued}

\begin{tabular}{|c|c|c|c|c|c|c|}
\hline \multicolumn{4}{|c|}{ 3. Kitchen waste } & \multicolumn{3}{|c|}{ 10. Miscellaneous } \\
\hline Compostable & 301 & Kitchen waste & Co & 1001 & Combustibles & NRe \\
\hline \multirow{2}{*}{ Non-compostable } & $301^{*}$ & Coconut/Durian shells & $\mathrm{NRe}$ & 1002 & Liquids_edible & Co \\
\hline & 302 & Hard animal bones & $\mathrm{NRe}$ & $1002^{*}$ & Liquids_inedible & $\mathrm{NRe}$ \\
\hline \multicolumn{4}{|c|}{ 4. Rubber and leather } & 1003 & Incombustibles (no ash) & $\mathrm{NRe}$ \\
\hline & 401 & Rubber and leather & $\mathrm{NRe}$ & 1004 & Ash & NRe \\
\hline \multicolumn{4}{|c|}{ 5. Grass and wood } & 1005 & Medical care & $\mathrm{NRe}$ \\
\hline \multirow{3}{*}{ Garden waste } & 501 & Garden waste & Co & 1006 & Batteries & $\mathrm{NRe}$ \\
\hline & $501^{*}$ & Garden waste & $\mathrm{NRe}$ & 1007 & E-waste & $\mathrm{NRe}$ \\
\hline & 502 & Flower & Co & 1008 & Others & $\mathrm{NRe}$ \\
\hline
\end{tabular}

*: Non-recyclable waste.

workers (including managers and serving workers), and number of guests as follows:

$$
W G R_{i}=\frac{D W A}{T N_{i}}
$$

where:

$W G R_{i}$ : Waste generation rate of each target hotel by four indicators: waste generation amount per room, that per bed, that per worker, and that per guest;

$D W A$ : Daily amount of waste generation of each target hotel;

$T N_{i}$ : Total number of unit of each target hotel by four indicators: number of rooms, number of beds, number of workers, and number of guests.

To determine whether the WGRs followed a normal/Gaussian distribution, the authors applied a Shapiro-Wilk test [27] [28] and found that the WGR distributions were significantly different from a normal distribution $(\mathrm{p}<0.001)$. Therefore, the authors employed non-parametric tests for further analysis.

In this study, the WGRs are reported as the mean with the $95 \%$ confidence interval $(95 \% \mathrm{CI})$. Non-parametric bootstrap with replacement sampling method was applied to determine the 95\% CI [12]. The authors assessed the difference in WGRs between hotel classes using a Kruskal-Wallis $\mathrm{H}$ test. And, a Mann-Whitney $\mathrm{U}$ test was used to identify significant differences between hotel classes by comparing all the pairs [28].

The composition of GW was analyzed using the categories and sub-categories listed in Table 2, and the recycling and composting potentials were aggregated based on this table.

To establish the solid waste stream from the hotel sector in Hue City, the authors estimated the total amount of generated waste, as well as its components by hotel class based on the WGR, waste separation rate, and waste composition survey results collected in this study. The detailed procedure is introduced in Section 3 after these results are elaborated. 


\section{Results and Discussion}

\subsection{Waste Separation Rate}

The waste separation rates of the target samples are summarized in Table 3 by the following 4 separation patterns: 1) recyclables and food residue separation, 2) recyclables separation only, 3) food residue separation only, and 4) no separation. The waste separation rates were calculated by dividing the number of targets applying specific waste separation activities by the total number of observed facilities by each hotel class.

$$
W S R_{i j}=\frac{N H S_{i j}}{T N H_{j}}
$$

where:

$W S R_{i j}$ : waste separation rate of separation pattern $i$ of hotel class $j$;

$N H S_{i j}$ : number of facilities with separation of separation pattern $i$ of hotel class $;$

$T N H_{j}$ : total number of facilities of hotel class $j$.

The results show that most of the target hotels ( 43 of 45 facilities) separated their waste. All 3- to 5-star hotels separated recyclables and food residue, while the waste separation rates of $\mathrm{GH}$ and 1-star hotels were lower. This tendency seems to be consistent with that found in a study on the hotel sector in Cairo, Egypt, which reported that high-class hotels successfully sorted waste at its source [29]. A study on hotels in India by Malik, S.M. and Kumar (2012) also suggested that small hotels have not paid attention to solid waste management practices due to a lack of funds and knowledge, which may be a reason for the difference in the waste separation rate between hotel classes [30].

\subsection{Waste Generation Rate and Influence Factors}

WGRs are reported to differ between hotel classes, services, and regions [31] [32] [33]. A similar tendency was observed in a study on the hotel sector in Halong, Vietnam (Byer et al., 2006), which reported daily waste generation rates of $203.3,114.3$, and $89 \mathrm{~kg} /$ day at 4-, 3-, and 2-star hotels, respectively [9].

Table 4 presents the total daily amounts of waste generated and WGRs (mean and $95 \%$ confidence interval) in three categories based on the hotel's typical separation manner, calculated by the following four denominators: room, bed,

Table 3. Waste separation status by hotel class.

\begin{tabular}{ccccccc}
\hline Waste separation activity & GH & 1-star & 2-star & 3-star & 4-star & 5-star \\
\hline Sample size (n) & 10 & 10 & 7 & 8 & 7 & 3 \\
Recyclables and food residue & $10 \%$ & $40 \%$ & $86 \%$ & $100 \%$ & $100 \%$ & $100 \%$ \\
Recyclables only & $70 \%$ & $30 \%$ & $14 \%$ & $0 \%$ & $0 \%$ & $0 \%$ \\
Food residue only & $10 \%$ & $20 \%$ & $0 \%$ & $0 \%$ & $0 \%$ & $0 \%$ \\
No separation & $10 \%$ & $10 \%$ & $0 \%$ & $0 \%$ & $0 \%$ & $0 \%$ \\
\hline
\end{tabular}


Table 4. Waste generation rates by hotel class.

\begin{tabular}{|c|c|c|c|c|c|c|c|c|c|}
\hline \multirow{2}{*}{ Category } & \multirow{2}{*}{$\mathrm{n}$} & \multicolumn{2}{|c|}{ Total waste } & \multicolumn{2}{|r|}{ GW } & \multicolumn{2}{|c|}{ SRe } & \multicolumn{2}{|r|}{ SFR } \\
\hline & & Mean & $95 \% \mathrm{CI}$ & Mean & $95 \% \mathrm{CI}$ & Mean & $95 \% \mathrm{CI}$ & Mean & $95 \% \mathrm{CI}$ \\
\hline \multicolumn{10}{|c|}{ Total daily waste generation amount (kg/day) } \\
\hline Guest house & 10 & 5.3 & $3.8-7.0$ & 4.2 & $2.8-5.9$ & 0.5 & $0.3-0.7$ & 0.6 & $0-1.4$ \\
\hline 1-star hotel & 10 & 7.8 & $6.0-9.8$ & 5.5 & $4.3-6.8$ & 0.7 & $0.3-1.0$ & 1.6 & $0.6-2.7$ \\
\hline 2-star hotel & 7 & 30.1 & $21.7-38.4$ & 15.5 & $12.4-18.6$ & 1.8 & $1.4-2.4$ & 12.8 & $7.2-18.9$ \\
\hline 3-star hotel & 8 & 68.8 & $58.8-179.0$ & 36.3 & $33.9-86.6$ & 2.5 & $4.3-11.8$ & 29.9 & $19.3-83.9$ \\
\hline 4-star hotel & 7 & 190.5 & $151.9-231.7$ & 102.1 & $81.4-126.9$ & 10.8 & $7.0-14.9$ & 77.6 & $58.5-97.2$ \\
\hline 5-star hotel & 3 & 271.8 & $223.1-490.6$ & 162.8 & $146.5-220.8$ & 14.9 & $9.1-42.1$ & 94.0 & $55.4-234.5$ \\
\hline \multicolumn{2}{|c|}{$\mathrm{K}-\mathrm{W}$ test (H value) } & \multicolumn{2}{|c|}{$38.058^{* * *}$} & \multicolumn{2}{|r|}{$37.321^{\star * *}$} & \multicolumn{2}{|c|}{$31.669^{* * *}$} & \multicolumn{2}{|r|}{$37.046^{* * *}$} \\
\hline \multicolumn{2}{|c|}{ Spearman's $\rho$} & \multicolumn{2}{|r|}{$0.917^{* *}$} & \multicolumn{2}{|r|}{$0.906^{* *}$} & \multicolumn{2}{|c|}{$0.813^{* *}$} & \multicolumn{2}{|r|}{$0.899^{* *}$} \\
\hline \multicolumn{10}{|c|}{ WGRs per room (g/room/day) } \\
\hline Guest house & 10 & 534 & $382-708$ & 400 & $272-567$ & 42 & $24-61$ & 95 & $0-224$ \\
\hline 1-star hotel & 10 & 387 & $300-488$ & 294 & $226-363$ & 34 & $18-52$ & 59 & $22-99$ \\
\hline 2-star hotel & 7 & 779 & $562-993$ & 415 & $332-498$ & 51 & $39-68$ & 313 & $175-460$ \\
\hline 3-star hotel & 8 & 1155 & $987-3007$ & 606 & $565-1443$ & 42 & $71-196$ & 507 & $328-1423$ \\
\hline 4-star hotel & 7 & 1455 & $1160-1770$ & 769 & $613-956$ & 86 & $56-119$ & 600 & $452-751$ \\
\hline 5-star hotel & 3 & 1607 & $1319-2901$ & 995 & $895-1349$ & 85 & $52-240$ & 526 & $310-1312$ \\
\hline \multicolumn{2}{|c|}{$\mathrm{K}-\mathrm{W}$ test ( $\mathrm{H}$ value) } & \multicolumn{2}{|c|}{$27.97^{* * *}$} & \multicolumn{2}{|r|}{$22.31^{* * *}$} & \multicolumn{2}{|c|}{$11.81^{\star * *}$} & \multicolumn{2}{|r|}{$27.49^{* * *}$} \\
\hline \multicolumn{2}{|c|}{ Spearman's $\rho$} & \multicolumn{2}{|r|}{$0.807^{\star *}$} & & $0.708^{\star \star}$ & & $453^{* *}$ & & $0.793^{* \star}$ \\
\hline & & & WGR & Rs per $b$ & bed (g/bed/day & & & & \\
\hline Guest house & 10 & 487 & $333-668$ & 369 & $234-548$ & 42 & $24-61$ & 75 & $0-187$ \\
\hline 1-star hotel & 10 & 265 & $194-339$ & 206 & $144-273$ & 21 & $11-32$ & 38 & $14-61$ \\
\hline 2-star hotel & 7 & 379 & $315-444$ & 211 & $178-245$ & 27 & $20-34$ & 142 & $82-199$ \\
\hline 3-star hotel & 8 & 613 & $711-2263$ & 323 & $399-1110$ & 22 & $48-150$ & 268 & $254-1048$ \\
\hline 4-star hotel & 7 & 821 & $632-1007$ & 431 & $337-535$ & 49 & $31-69$ & 341 & $246-431$ \\
\hline 5-star hotel & 3 & 1208 & $702-1528$ & 757 & $445-710$ & 63 & $28-126$ & 388 & $165-691$ \\
\hline $\mathrm{K}-\mathrm{W}$ test $(\mathrm{H}$ & alue) & & $4.31^{* * *}$ & & $17.22^{\star *}$ & & $0.80^{*}$ & & $27.73^{* * *}$ \\
\hline Spearman' & & & $0.779^{* *}$ & & $0.573^{* *}$ & & .291 & & $0.833^{* *}$ \\
\hline & & & WGRs & per gu & dest (g/guest/d & & & & \\
\hline Guest house & 5 & 604 & $424-785$ & 432 & $237-629$ & 30 & $4-56$ & 141 & $8-303$ \\
\hline 1-star hotel & 4 & 603 & $483-724$ & 466 & $313-641$ & 30 & $0-64$ & 107 & $29-184$ \\
\hline 2-star hotel & 4 & 481 & $383-610$ & 300 & $233-381$ & 26 & $18-40$ & 155 & $59-244$ \\
\hline 3-star hotel & 7 & 1706 & $1347-2136$ & 963 & $754-1169$ & 65 & $38-91$ & 717 & $516-993$ \\
\hline 4-star hotel & 6 & 2322 & $1705-3112$ & 1175 & $855-1504$ & 147 & $107-192$ & 1001 & $697-1456$ \\
\hline 5-star hotel & 3 & 6568 & $2583-10061$ & 4162 & $1175-6148$ & 301 & $223-409$ & 2104 & $1185-3504$ \\
\hline $\mathrm{K}-\mathrm{W}$ test $(\mathrm{H}$ & alue) & & $4.056^{\star * *}$ & & $20.108^{\star * *}$ & & $117^{\star \star}$ & & $22.746^{* * *}$ \\
\hline Spearman' & & & $0.747^{* *}$ & & $0.645^{\star *}$ & & $746^{\star *}$ & & $0.809^{* *}$ \\
\hline
\end{tabular}


Continued

\begin{tabular}{ccccccccccc}
\hline \multicolumn{1}{c}{ WGRs per worker (g/worker/day) } \\
Guest house & 10 & 2144 & $1455-3170$ & 1756 & $1057-2706$ & 216 & $107-357$ & 172 & $0-411$ \\
1-star hotel & 10 & 786 & $635-941$ & 604 & $466-751$ & 65 & $33-97$ & 117 & $37-215$ \\
2-star hotel & 7 & 1431 & $904-2002$ & 756 & $536-1016$ & 88 & $68-111$ & 587 & $247-934$ \\
3-star hotel & 7 & 1403 & $1075-6289$ & 738 & $605-2957$ & 53 & $15-338$ & 611 & $576-3092$ \\
4-star hotel & 7 & 1151 & $892-1413$ & 606 & $470-758$ & 68 & $43-94$ & 476 & $351-600$ \\
5-star hotel & 3 & 1263 & $949-2498$ & 757 & $588-1161$ & 70 & $38-206$ & 436 & $249-1130$ \\
K-W test (H value) & $18.87^{* *}$ & & $13.87^{*}$ & & 9.12 & & $18.05^{* *}$ \\
\multicolumn{2}{l}{ Spearman's $\rho$} & & -0.049 & & -0.353 & -0.297 & $0.638^{* *}$ \\
\hline
\end{tabular}

K-W test: $\mathrm{H}$ value by Kruskal-Wallis test by ranks; Spearman's $\rho$. Rank correlation coefficient by Spearman method; ${ }^{*}: \mathrm{p}<0.05 ;{ }^{* *}: \mathrm{p}<0.01{ }^{* * *}: \mathrm{p}<0.001$.

guest, and worker. Table 4 also shows the results of the Kruskal-Wallis $\mathrm{H}$ tests and Spearman's rank correlation analyses.

Regarding the difference between hotel classes, the rank correlations between total daily amounts of waste generated and WGRs and room, bed, and guest were significantly positive (excluding the WGR of SRe per bed). The 5-star hotels exhibited the highest total daily waste generation $(271.8 \mathrm{~kg} /$ day), followed by 4-star hotels (190.5 kg/day), 3-star hotels $(68.8 \mathrm{~kg} /$ day), 2-star hotels (30.1 $\mathrm{kg}$ /day), 1-star hotels $(7.8 \mathrm{~kg} /$ day), and GHs $(5.3 \mathrm{~kg} /$ day). The daily waste generation and WGRs increased as the hotel increased. The results were consistent with those in past studies on the hotel sector [17] [31] [34].

For the per-guest WGRs, 5-star hotels generated an average of 6.57 $\mathrm{kg} /$ guest/day, followed by 4 -star hotels $(2.32 \mathrm{~kg} /$ guest/day), 3-star hotels $(1.71$ $\mathrm{kg} /$ guest/day), 2 -star hotels ( $0.48 \mathrm{~kg} /$ guest/day), 1-star hotels $(0.60 \mathrm{~kg} /$ guest/day), and GHs $(0.60 \mathrm{~kg} /$ guest/day).

According to some previous studies on the WGRs of the hotel sector in Asia [17] [35] [36], the per-guest WGRs range from 0.8 to $3.33 \mathrm{~kg} /$ guest/day, which overlaps the range of 0.60 to $6.57 \mathrm{~kg} /$ guest/day presented in this study.

The per-worker WGRs of GW and SRe were not significantly rank correlated with hotel class, and those by GHs were highest. The number of workers employed by GH was generally much smaller than that employed by higher-class hotels, which could have caused the increased per-worker WGRs at GHs. The GW and SRe WGRs of 2- to 5-star hotels were similar, despite higher-class hotels employing greater numbers of workers. This could be attributed to the higher WGRs per room, bed, and guest exhibited by higher-class hotels.

The SFR WGRs was significantly rank correlated with hotel class. Most 3-5-star some 2-star, and a few 1-star hotels and GHs provide food and beverage services, such as restaurants and coffee shops/bars, which could be a possible reason for the higher SFR WGRs of higher-class hotels.

Based on the results of the Kruskal-Wallis $\mathrm{H}$ test, there were significant differences in the total per-room WGRs between hotel classes $\left(\chi^{2}(5)=27.97, \mathrm{p}<0.001\right)$, 
and significant differences were also detected for other WGRs per bed, guest, and worker. To clarify the significant differences between hotel classes, a Mann-Whitney $U$ test was conducted by comparing all WGR pairs. The results suggested that hotel classes could be re-grouped into: 1) Low (guest house and 1-star hotel); 2) Middle (2- and 3-star hotels); and 3) High (4- and 5-star hotels) classes. The WGRs were recalculated by these three hotel classes and presented in Table 5.

The authors also examined the influences of factors such as food service (breakfast, dining) and events (wedding party, conference) on WGRs. The Mann Whitney $U$ test for each class indicated that there was no significant difference ( $p>0.05)$ between hotels with and without food services/events.

\subsection{Waste Composition and Recycling Potential}

Table 6 presents the physical composition (in percentage) of GW by hotel class. Food waste accounted for the largest proportion of GW for all hotel classes, and was highest for GHs (57.4\%), followed by 5- (56.6\%), 1- (51.0\%), 3- (48.4\%), 4(44.1\%), and 2-star hotels (40.9\%). These results are similar to those from a study on ten hotels in Danang, Vietnam, by Otoma et al. (2013), who reported that food waste accounted for $65.5 \%$ of waste. Paper accounted for the second largest proportion, ranging from $10.1 \%$ (5-star hotel) to $23.9 \%$ (1-star hotel), followed by plastic, ranging from $10.7 \%$ (2-star hotel) to $15.5 \%(\mathrm{GH})$.

Table 6 also presents the waste composting and recycling potentials from GW. The composting potential was highest for most hotel classes, especially low-class hotels (53.2\%). The recycling potential was highest for 2-star hotels, at $38.5 \%$, followed by 4 -star hotels (35.1\%) and GHs (33.5\%).

Plastic containers and packaging, paper containers and packaging, and paper products were the major three components that could be recycled, accounting for over half of the recycling potential for most hotel classes (excluding 2-star hotels). Plastic containers and packaging accounted for a major proportion of the recycling potential at low-class hotels (10.2\%). In contrast, paper products

Table 5. Waste generation rates by three hotel classes.

\begin{tabular}{|c|c|c|c|c|c|c|c|c|c|}
\hline \multirow{2}{*}{ Category } & \multirow{2}{*}{$\mathrm{n}$} & \multicolumn{2}{|c|}{ Total waste } & \multicolumn{2}{|r|}{ GW } & \multicolumn{2}{|c|}{$\mathrm{SRe}$} & \multicolumn{2}{|r|}{ SFR } \\
\hline & & Mean & $95 \% \mathrm{CI}$ & Mean & $95 \% \mathrm{CI}$ & Mean & $95 \% \mathrm{CI}$ & Mean & $95 \% \mathrm{CI}$ \\
\hline \multicolumn{10}{|c|}{ WGRs per room (g/room/day) } \\
\hline Low-class hotels ${ }^{[1]}$ & 20 & 461 & $371-585$ & 347 & $295-486$ & 38 & $30-55$ & 77 & $9-104$ \\
\hline Middle-class hotels $^{[2]}$ & 15 & 980 & $769-1205$ & 517 & $413-621$ & 46 & $34-59$ & 417 & $299-544$ \\
\hline High-class hotels ${ }^{[3]}$ & 10 & 1501 & $1251-1772$ & 837 & $666-1048$ & 86 & $61-111$ & 578 & $470-689$ \\
\hline $\mathrm{K}-\mathrm{W}$ test ( $\mathrm{H}$ value) & & \multicolumn{2}{|c|}{$25.582^{* * *}$} & \multicolumn{2}{|c|}{$19.075^{\star * *}$} & \multicolumn{2}{|c|}{$10.304^{* * *}$} & \multicolumn{2}{|c|}{$26.138^{\star * *}$} \\
\hline Spearman's $\rho$ & & \multicolumn{2}{|r|}{$0.843^{* *}$} & \multicolumn{2}{|c|}{$0.764^{\star *}$} & \multicolumn{2}{|c|}{$0.493^{* *}$} & \multicolumn{2}{|c|}{$0.824^{\star *}$} \\
\hline
\end{tabular}

${ }^{[1]}$ Low-class hotels: Guesthouse and 1 star hotels; ${ }^{[2]}$ Middle-class hotels: 2 and 3 star hotels; ${ }^{[3]}$ High-class hotels: 4 and 5 star hotels. K-W test: $\mathrm{H}$ value by Kruskal-Wallis test by ranks; Spearman's $\rho$ : Rank correlation coefficient by Spearman method; ${ }^{* *}: \mathrm{p}<0.01{ }^{* * *}: \mathrm{p}<0.001$. 
Table 6. Physical composition of GW from the hotel sector by hotel class (\%).

\begin{tabular}{|c|c|c|c|c|c|c|c|c|c|}
\hline \multirow{2}{*}{ Component } & \multicolumn{9}{|c|}{ Hotel class } \\
\hline & $\mathrm{GH}$ & 1-star & 2-star & 3-star & 4-star & 5 -star & Low $^{[1]}$ & Middle $^{[2]}$ & $\operatorname{High}^{[3]}$ \\
\hline Sample size (n) & 8 & 4 & 3 & 3 & 2 & 1 & 12 & 6 & 3 \\
\hline Plastic & 15.5 & 12.0 & 10.7 & 11.8 & 11.5 & 12.5 & 14.4 & 11.2 & 11.9 \\
\hline Paper & 13.5 & 23.9 & 16.7 & 14.8 & 20.3 & 10.1 & 17.0 & 15.8 & 16.9 \\
\hline Food waste & 57.4 & 51.0 & 40.9 & 48.4 & 44.1 & 56.6 & 55.2 & 44.7 & 48.3 \\
\hline Rubber \& leather & 0.3 & 0.2 & 2.8 & 0.7 & 0.2 & 0.0 & 0.2 & 1.8 & 0.2 \\
\hline Grass \& wood & 2.0 & 7.2 & 10.7 & 8.5 & 6.4 & 7.0 & 3.7 & 9.6 & 6.6 \\
\hline Textile & 2.4 & 2.2 & 7.7 & 1.6 & 4.0 & 0.9 & 2.3 & 4.7 & 3.0 \\
\hline Metal & 1.3 & 0.2 & 1.7 & 0.7 & 0.4 & 0.3 & 1.0 & 1.2 & 0.3 \\
\hline Glass & 3.8 & 1.0 & 3.3 & 0.3 & 1.4 & 1.1 & 2.9 & 1.8 & 1.3 \\
\hline Ceramic & 0.6 & 0.0 & 0.0 & 0.3 & 0.6 & 7.4 & 0.4 & 0.1 & 2.9 \\
\hline Miscellaneous & 3.2 & 2.4 & 5.5 & 12.9 & 11.0 & 4.2 & 2.9 & 9.2 & 8.7 \\
\hline Composting potential & 57.9 & 43.9 & 38.0 & 52.4 & 48.7 & 48.8 & 53.2 & 45.2 & 48.7 \\
\hline Food waste & 56.0 & 41.0 & 27.9 & 44.8 & 42.5 & 45.7 & 51.0 & 36.3 & 43.6 \\
\hline Garden waste & 1.9 & 2.9 & 10.2 & 7.6 & 6.2 & 3.0 & 2.2 & 8.9 & 5.2 \\
\hline Recycling potential & 33.5 & 31.5 & 38.5 & 28.6 & 35.1 & 19.3 & 32.8 & 33.6 & 29.8 \\
\hline Plastic-C\&P ${ }^{a}$ & 11.1 & 8.6 & 6.9 & 8.1 & 7.1 & 4.5 & 10.2 & 7.5 & 6.2 \\
\hline Plastic-Product & 2.7 & 1.1 & 1.5 & 2.3 & 1.4 & 1.1 & 2.1 & 1.9 & 1.3 \\
\hline Plastic-Other & 0.0 & 0.6 & 0.9 & 0.0 & 0.6 & 0.0 & 0.2 & 0.5 & 0.4 \\
\hline Paper-C\&P ${ }^{a}$ & 4.6 & 7.4 & 4.1 & 5.1 & 4.1 & 3.3 & 5.5 & 4.6 & 3.8 \\
\hline Paper-Product & 7.4 & 8.4 & 7.2 & 8.2 & 14.3 & 5.7 & 7.7 & 7.7 & 11.5 \\
\hline Paper-Other & 1.6 & 1.0 & 1.8 & 0.5 & 0.8 & 1.0 & 1.4 & 1.1 & 0.9 \\
\hline Other material & 6.0 & 4.3 & 16.1 & 4.4 & 6.8 & 3.7 & 5.6 & 10.2 & 5.7 \\
\hline Non-recyclable & 8.6 & 24.6 & 23.5 & 19.0 & 16.2 & 31.9 & 13.9 & 21.2 & 21.4 \\
\hline
\end{tabular}

${ }^{\mathrm{a}} \mathrm{C} \& \mathrm{P}$ : containers and packaging. ${ }^{[1]}$ Low-class hotels: Guesthouse and 1 star hotels; ${ }^{[2]}$ Middle-class hotels: 2 and 3 star hotels; ${ }^{[3]}$ High-class hotels: 4 and 5 star hotels.

dominated the recycling potential at high-class hotels (11.5\%). Although the hotel sector in Hue City conducts recycling using informal sectors such as junk-buyers and livestock breeders, substantial amounts of compostable and recyclable waste still remain in GW. Recycling activities tend to focus on materials that are easily separated and high value, such as beverage containers, while items that are not easily separated, such as a small amount of recyclables and smelly organic waste, are often put into GW without separation.

\subsection{Estimation of Waste Generation}

The estimation procedure followed the methodology reported by Matsui et al. (2018) [12]. To depict the solid waste stream from the hotel sector in Hue City, 
the authors estimated the total waste generation and its components by hotel class based on the per-room WGRs (Table 6), waste composition (Table 6), waste separation rates (Table 7), and total number of rooms (Table 7) by hotel class, as follows.

For the facilities separating both recyclables and food residue, the total waste generation could be divided into the following five components based on the waste's composition and waste measurement survey data: recycling potential, composting potential, non-recoverable, separated recyclables, and separated food residue. For the facilities with other types of separation procedures, such as "recyclables only", "food residue only", and "no separation", the authors estimated the amounts of waste generated for the five components using the waste composition data of facilities conducting "recyclables and food residue separation" according to assumed component allocations, as shown in Table 8. The authors assumed that the unseparated recyclables and food residue were discharged as a part of the recycling and composting potentials in GW at these facilities.

Based on the waste composition data of facilities separating "recyclables and food residue", the total waste generation and its five components for each hotel class was calculated using the following equations:

Table 7. Waste separation status and number of rooms in Hue City by hotel class.

\begin{tabular}{|c|c|c|c|}
\hline & Low-class $^{[a]}$ & Middle-class $^{[\mathrm{b}]}$ & High-class $^{[\mathrm{c}}$ \\
\hline \multicolumn{4}{|l|}{ Waste separation status } \\
\hline Sample size $(n)$ & 20 & 15 & 10 \\
\hline Recyclables and food residue & $25 \%$ & $93.5 \%$ & $100 \%$ \\
\hline Recyclables only & $50 \%$ & $6.5 \%$ & $0 \%$ \\
\hline Food residue only & $15 \%$ & $0 \%$ & $0 \%$ \\
\hline No separation & $10 \%$ & $0 \%$ & $0 \%$ \\
\hline \multicolumn{4}{|l|}{ Number of hotels in Hue City } \\
\hline Facilities & 344 & 43 & 15 \\
\hline Rooms & 3582 & 2024 & 2157 \\
\hline
\end{tabular}

${ }^{[a]}$ Low-class hotel: Guesthouse and 1 star hotels; ${ }^{[b]}$ Middle-class hotel: 2 and 3 star hotels; ${ }^{[c]}$ High-class hotel: 4 and 5 star hotels. Source: General statistics office, 2015.

Table 8. Assumed component allocations by waste separation status.

\begin{tabular}{|c|c|c|c|c|c|c|}
\hline \multirow[b]{2}{*}{ Separation status } & \multirow[b]{2}{*}{ Rate } & \multicolumn{3}{|c|}{ General waste } & \multirow{2}{*}{$\begin{array}{l}\text { Separated } \\
\text { recyclables }\end{array}$} & \multirow{2}{*}{$\begin{array}{l}\text { Separated } \\
\text { food residue }\end{array}$} \\
\hline & & $\begin{array}{l}\text { Recycling } \\
\text { potential }\end{array}$ & $\begin{array}{c}\text { Composting } \\
\text { potential }\end{array}$ & Non-recoverable & & \\
\hline Recyclables and food residue separation & $a_{1}$ & $\operatorname{Re}$ & Co & $\mathrm{NRe}$ & $\mathrm{SRe}$ & SFR \\
\hline Recyclables separation only & $a_{2}$ & $\operatorname{Re}$ & $\mathrm{Co}+\mathrm{SFR}$ & $\mathrm{NRe}$ & $\mathrm{SRe}$ & - \\
\hline Food residue separation only & $a_{3}$ & $\operatorname{Re}+\mathrm{SRe}$ & Co & $\mathrm{NRe}$ & - & SFR \\
\hline No separation & $a_{4}$ & $\mathrm{Re}+\mathrm{SRe}$ & $\mathrm{Co}+\mathrm{SFR}$ & $\mathrm{NRe}$ & - & - \\
\hline
\end{tabular}




$$
\begin{gathered}
\text { Recycling potential }=n_{i} *\left[\left(a_{1}+a_{2}\right) * \mathrm{Re}+\left(a_{3}+a_{4}\right) *(\mathrm{Re}+\mathrm{SRe})\right] \\
\text { Composting potential }=n_{i} *\left[\left(a_{1}+a_{3}\right) * \mathrm{Co}+\left(a_{2}+a_{4}\right) *(\mathrm{Co}+\mathrm{SFR})\right] \\
\text { Non-recyclable }=n_{i} *\left(a_{1}+a_{2}+a_{3}+a_{4}\right) * \mathrm{NRe} \\
\text { Separated recyclables }=n_{i} *\left(a_{1}+a_{2}\right) * \mathrm{SRe} \\
\text { Separated food residue }=n_{i} *\left(a_{1}+a_{3}\right) * \mathrm{SFR}
\end{gathered}
$$

Total waste generation I = Recycling potential + Composting potential + Non-recyclable + Separated recyclables + Separated food residue.

Where $n_{i}$ is the total number of rooms in Hue City by each hotel class (Low-class, Middle-class, High-class).

To estimate the $95 \%$ CI of the total waste generation and its five components from the hotel sector in Hue City, the Monte Carlo simulation by non-parametric bootstrap method with return was applied [12] [37].

The results of the total waste generation and its components by the Hue hotel sector are shown in Figure 2. The figure shows both the results of point estimation by the average value of each parameter and those of the $95 \%$ CI. From the point estimation results, the total waste generation of the hotel sector in Hue City was estimated to be 6.88 tons/day, 4.37 tons/day (64\%) of which was GW, 2.13 tons/day (30\%) was SFR, and 0.38 tons/day (6\%) was SRe. The estimated composting and recycling potentials remaining in the GW were 2.57 (37\%) and 0.87 tons/day (13\%), respectively. The results show that the amount of waste treated at the landfill site could be reduced by $78 \%$, from 4.37 to 0.94 tons/day, by improving waste separation at source.

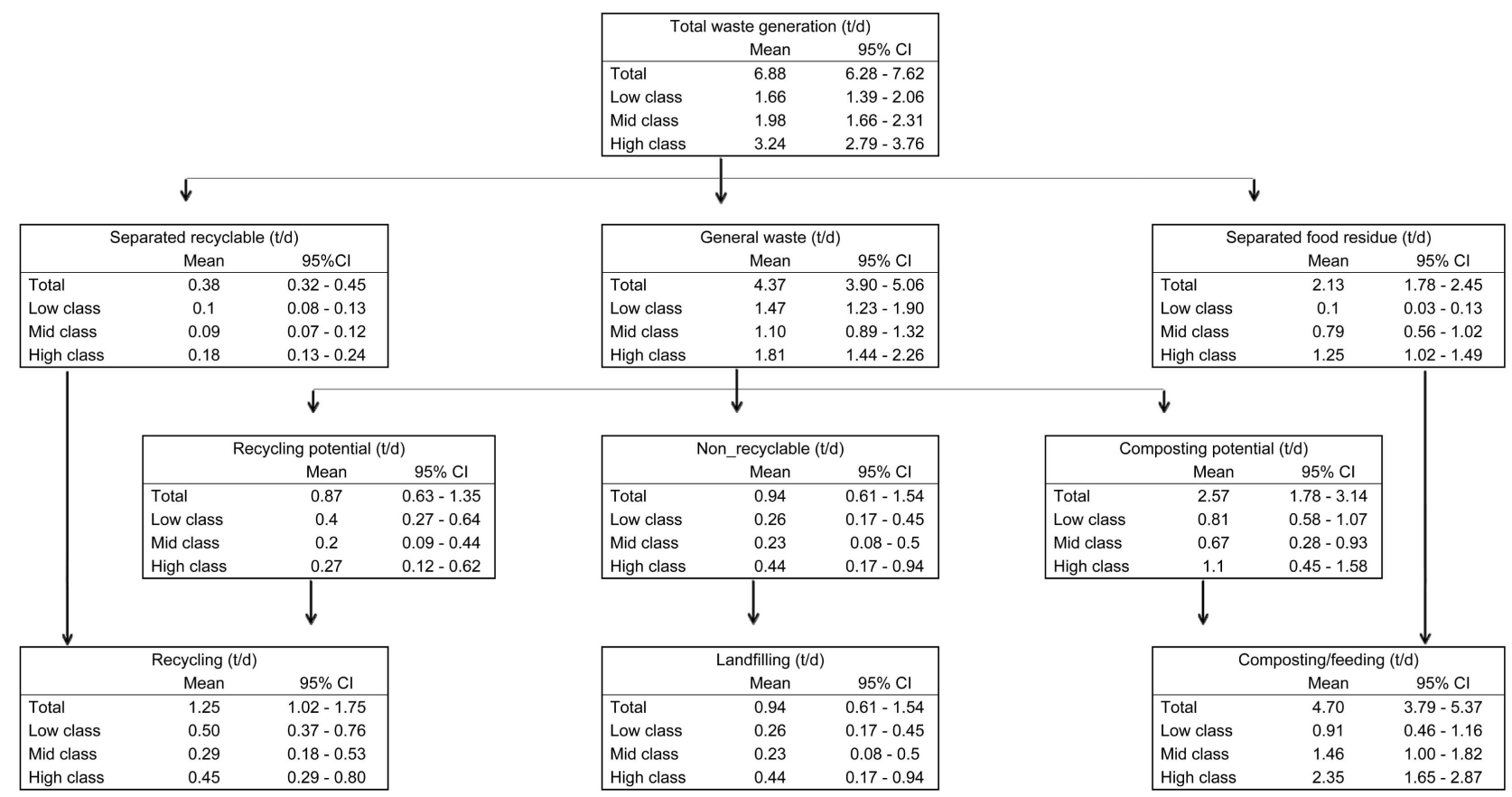

Figure 2. Estimated waste stream of the hotel sector in Hue City. 
High-class hotels contributed the highest amount of waste to the total amount generated by the hotel sector, at 3.24 tons/day (47\%), followed by middle-class hotels at 1.98 tons/day (29\%), and low-class hotels at 1.66 tons/day (24\%). The recycling potential was highest for low-class hotels at 0.4 tons/day (6\%), and the composting potential was highest for high-class hotels at 1.10 tons/day $(16 \%)$.

The $95 \%$ CI of the total waste generation by the hotel sector was $6.28-7.62$ tons/day, and the $95 \%$ CIs of the separated recyclable and separated food residue were $0.32-0.45$ and $1.78-2.45$ tons/day, respectively.

To estimate the impact of each parameter used for the confidence interval estimation of total waste generation, the authors also conducted sensitivity analysis by squaring the Spearman's Rank Coefficients of each parameter, summing the results, and adjusting them to $100 \%$ [12] [38] [39]. The results presented in Figure 3 show that GW produced by high-class hotels contributed the most to sensitivity (38.2\%), followed by GW produced by low-class hotels (22.3\%), SFR produced by middle-class hotels (12.4\%), and SFR produced by high-class hotels (11.7\%). The GW produced by high-class hotels was the largest contributor, constituting $26 \%$ of the total waste generation. Therefore, it contributed the most to the sensitivity analysis result. To improve the reliability of the estimated total waste generation, the parameters with greater impacts on uncertainty require additional data collection and/or modeling by influence factors, which would reduce the overall uncertainty of the results.

\section{Conclusions}

This study assessed the solid waste generation and recycling potential of the hotel sector in Hue City, Vietnam. The authors analyzed waste generation rates (WGRs) and composition in detail for 45 targeted establishments. The WGRs were also categorized considering the amount of waste collected by informal

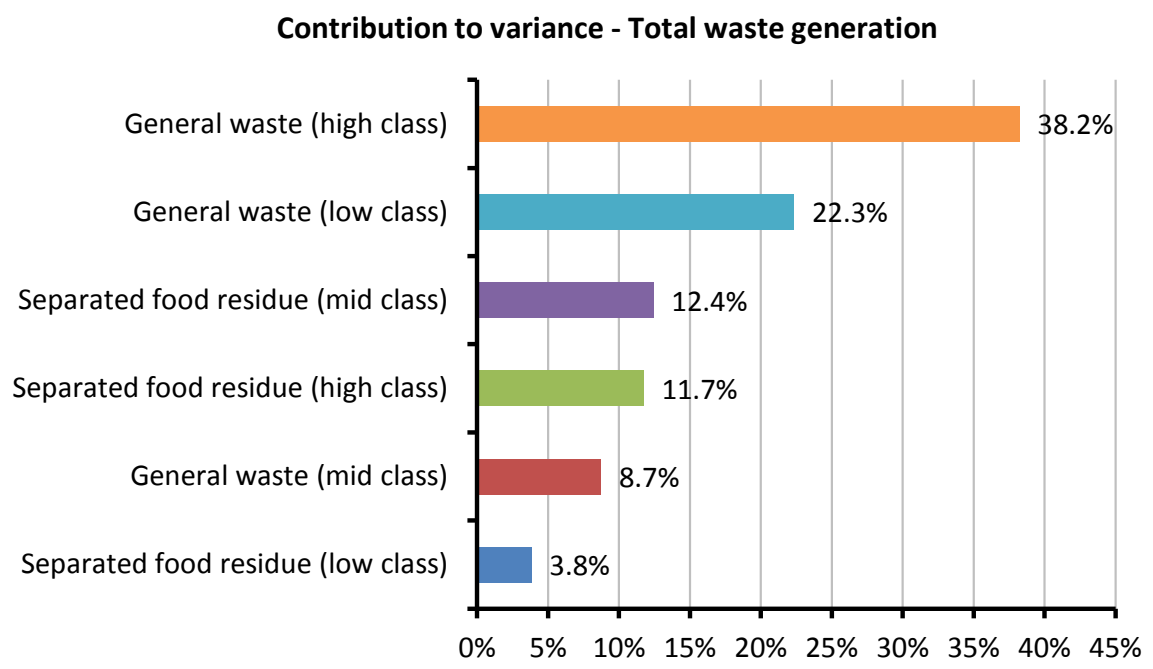

Figure 3. Sensitivity analysis of the total waste generation of the hotel sector. 
sectors: general waste (GW), separated recyclables (SRe), and separated food residue (SFR). Some key findings of this study are outlined below.

1) Participation in waste separation by the hotel sector in Hue City was very high; $95.56 \%$ of the target establishments separated waste at its source. Food waste separation was common among middle- and high-class hotels (from 2- to 5 -stars) where food and beverage services (such as restaurants or café bars) were provided.

2) The average total daily waste generation per facility was highest at 5-star hotels $(271.8 \mathrm{~kg} /$ day), followed by $4-(190.5 \mathrm{~kg} /$ day $), 3-(68.8 \mathrm{~kg} /$ day $), 2-(30.1$ $\mathrm{kg} /$ day), and 1-star hotels ( $7.8 \mathrm{~kg} /$ day), and guest houses $(5.3 \mathrm{~kg} /$ day $)$.

3) The total per-room WGRs were highest for 5-star hotels at 1.61 $\mathrm{kg} / \mathrm{room} / \mathrm{day}$, and lowest for 1-star hotels $(0.39 \mathrm{~kg} / \mathrm{room} / \mathrm{day})$. In addition, the total per-guest WGRs were highest for 5-star hotels at $6.57 \mathrm{~kg} /$ guest/day, and lowest for 1-star hotels and guest houses $(0.6 \mathrm{~kg} /$ guest/day). The rank correlations between the hotel classes and WGRs per room, bed, and guest (excluding the WGR of SRe per bed) were significantly positive.

4) Food waste constituted the largest proportion of GW within a range of $40.9 \%-57.4 \%$. The composting and recycling potentials were within ranges of $38.0 \%-57.9 \%$ and $19.3 \%-38.5 \%$, respectively. Plastic containers and packaging, paper containers and packaging, and paper products were the three major components, accounting for over half of the recycling potential of most hotel classes. Plastic containers and packaging accounted for a major proportion of the recycling potential at low-class hotels (10.2\%), while paper products were dominant at high-class hotels (11.5\%).

5) The total waste generation of the hotel sector in Hue City was estimated to be 6.88 tons/day $(6.28-7.62$ tons/day, 95\% CI). The remaining recycling and compostable potentials of $\mathrm{GW}$ accounted for 0.87 tons/day (0.63 - 1.35 tons/day, $95 \% \mathrm{CI})$ and 2.57 tons/day (1.78 - 3.14, 95\% CI), respectively. Therefore, the total amount of non-recyclable waste delivered to landfill sites can be reduced from the current 4.37 tons/day (3.90 - 5.06 tons/day, 95\% CI) to 0.94 tons/day (0.61 - 1.54 tons/day, $95 \% \mathrm{CI}$ ).

6) The recycling potential of GW was highest for low-class hotels at 0.4 tons/day (0.27 - 0.64 tons/day, 95\% CI), and the composting potential of GW was highest for high-class hotels at 1.10 tons/day (0.45 - 1.58 tons/day, 95\% CI). High-class hotels should be considered as priority targets for a 3R promotion campaign in the future.

7) Based on the sensitivity analysis, the GW produced by high-class hotels had the highest influence $(38.2 \%)$ on the estimated total waste generation, followed by GW produced by low-class hotels (22.3\%), SFR from middle-class hotels $(12.4 \%)$, and SFR from high-class hotels (11.7\%). To improve the reliability of the estimated total waste generation, the parameters with greater impacts on uncertainty require additional data collection and/or modeling by influence factors to reduce the overall uncertainty of the results. 


\section{References}

[1] Kumar, S. (2016) Municipal Solid Waste Management in Developing Countries. CRC Press, Boca Raton. https://doi.org/10.1201/9781315369457

[2] JICA (2017) Vietnam Waste at a Glance. Hanoi.

[3] Otoma, S., Hoang, H., Hong, H., Miyazaki, I. and Diaz, R. (2013) A Survey on Municipal Solid Waste and Residents' Awareness in Da Nang City, Vietnam. Journal of Material Cycles and Waste Management, 15, 187-194. https://doi.org/10.1007/s10163-012-0109-2

[4] Thanh, N.P., Matsui, Y. and Fujiwara, T. (2010) Household Solid Waste Generation and Characteristic in a Mekong Delta City, Vietnam. Journal of Environmental Management, 91, 2307-2321. https://doi.org/10.1016/j.jenvman.2010.06.016

[5] Thanh, N.P. and Matsui, Y. (2013) Assessment of Potential Impacts of Municipal Solid Waste Treatment Alternatives by Using Life Cycle Approach: A Case Study in Vietnam. Environmental Monitoring and Assessment, 185, 7993-8004.

https://doi.org/10.1007/s10661-013-3149-8

[6] Vietnam Government (2015) Decree on Management of Waste and Discarded Materials. Decree No. 38/2015/ND-CP, Hanoi.

[7] Vietnam Government (2011) National Statement of Environment 2011. Hanoi.

[8] Kato, T., Thi, D., Pham, X., Hoang, H., Xue, Y. and Van Tran, Q. (2012) Food Residue Recycling by Swine Breeders in a Developing Economy: A Case Study in Da Nang, Viet Nam. Waste Management, 32, 2431-2438. https://doi.org/10.1016/j.wasman.2012.07.015

[9] Byer, P.H., Hoang, C.P., Nguyen, T.T.T., Chopra, S., Maclaren, V. and Haight, M. (2006) Household, Hotel and Market Waste Audits for Composting in Vietnam and Laos. Waste Management and Research, 24, 465-472. https://doi.org/10.1177/0734242X06068067

[10] Williams, P.T. (2005) Waste Treatment and Disposal. John Wiley \& Sons, West Sussex.

[11] Bandara, N.J.G.J., Hettiaratchi, J.P.A., Wirasinghe, S.C. and Pilapiiya, S. (2007) Relation of Waste Generation and Composition to Socio-Economic Factors: A Case Study. Environmental Monitoring and Assessment, 135, 31-39. https://doi.org/10.1007/s10661-007-9705-3

[12] Matsui, Y., Son, L.H., Trang, D.T.T, Dang, N.H., Mai, T.V.C. and Thanh, N.P. (2018) An Estimation of Solid Waste Generation and Recycling Potential at Food and Beverage Service Sectors: A Case Study in Hue, Vietnam. Journal of Environmental and Social Sciences, 5, 134.

[13] Matsui, Y., Trang, D.T.T. and Thanh, N.P. (2015) Estimation of Waste Generation and Recycling Potential from Traditional Market: A Case Study in Hue City, Vietnam. Journal of Environmental Protection, 6, 308-320. https://doi.org/10.4236/jep.2015.64031

[14] Bohdanowicz, P. and Martinac, I. (2007) Determinants and Benchmarking of Resource Consumption in Hotels-Case Study of Hilton International and Scandic in Europe. Energy and Buildings, 39, 82-95.

https://doi.org/10.1016/j.enbuild.2006.05.005

[15] Oreja-Rodríguez, J.R. and Armas-Cruz, Y. (2012) Environmental Performance in the Hotel Sector: The Case of the Western Canary Islands. Journal of Cleaner Production, 29-30, 64-72. https://doi.org/10.1016/j.jclepro.2012.02.012

[16] Radwan, H.R.I., Jones, E. and Minoli, D. (2010) Managing Solid Waste in Small 
Hotels. Journal of Sustainable Tourism, 18, 175-190. https://doi.org/10.1080/09669580903373946

[17] Omidiani, A. and Hashemihezaveh, S. (2016) Waste Management in Hotel Industry in India: A Review. International Journal of Scientific and Research Publications, 6, 670-680.

[18] Yu, C.-C. and Maclaren, V. (1995) A Comparison of Two Waste Stream Quantification and Characterization Methodologies. Waste Management and Research, 13, 343-361. https://doi.org/10.1177/0734242X9501300406

[19] Trung, D.N. and Kumar, S. (2005) Resource Use and Waste Management in Vietnam Hotel Industry. Journal of Cleaner Production, 13, 109-116. https://doi.org/10.1016/j.jclepro.2003.12.014

[20] Giang, H.M., Fujiwara, T. and Pham Phu, S.T. (2017) Municipal Solid Waste Generation and Composition in a Tourist City-Hoi An, Vietnam. Journal of Japan Society of Civil Engineers, 5, 123-132.

[21] General Statistics Office (2015) Hue Statistical Yearbook. Hue.

[22] Vietnam Government (2014) Approval for Adjustments to General Planning for Hue City to 2030 and a Vision to 2050. Decision No. 649/QD-TTg, Hanoi.

[23] Hue Urban Environment and Public Works State Company (2013) Report on Solid Waste Management of Hue. Hue.

[24] Hue's People Committee (2013) Master Plan of Touris Sector in Hue. Hue.

[25] Vietnam Ministry of Science and Technology (2009) Vietnam Standards of Tourist Guest House. Hanoi.

[26] Vietnam Ministry of Science and Technology (2009) Vietnam Hotel Classification. Hanoi.

[27] Thode, H.C. (2002) Testing for Normality. CRC Press, Boca Raton. https://doi.org/10.1201/9780203910894

[28] Field, A. (2009) Discovering Statistics Using SPSS. SAGE Publications Ltd., London.

[29] Ball, S. and Taleb, M.A. (2011) Benchmarking Waste Disposal in the Egyptian Hotel Industry. Tourism and Hospitality Research, 11, 1-18. https://doi.org/10.1057/thr.2010.16

[30] Malik, S. and Kumar, S.M. (2012) Management of Hotel Waste: A Case Study of Small Hotels of Haryana State. A Journal of Economics and Management, 1, 1-13.

[31] Singh, N., Cranage, D.A. and Nath, A. (2014) Estimation of GHG Emission from Hotel Industry. Anatolia, 25, 39-48. https://doi.org/10.1080/13032917.2013.822817

[32] Muñoz, E. and Navia, R. (2015) Waste Management in Touristic Regions. Waste Management and Research, 33, 593-594. https://doi.org/10.1177/0734242X15594982

[33] Pirani, S.I. and Arafat, H.A. (2014) Solid Waste Management in the Hospitality Industry: A Review. Journal of Environmental Management, 146, 320-336. https://doi.org/10.1016/j.jenvman.2014.07.038

[34] Erdogan, N. and Baris, E. (2007) Environmental Protection Programs and Conservation Practices of Hotels in Ankara, Turkey. Tourism Management, 28, 604-614. https://doi.org/10.1016/j.tourman.2006.07.003

[35] Tang, J. (2004) A Case Study of a Hotel Solid Waste Management Program in Bali, Indonesia. University of Waterloo, Waterloo.

[36] Chan, W.W. and Lam, J. (2001) Environmental Accounting of Municipal Solid Waste Originating from Rooms and Restaurants in the Hong Kong Hotel Industry. 
Journal of Hospitality \& Tourism Research, 25, 371-385.

https://doi.org/10.1177/109634800102500402

[37] Simar, L. and Wilson, P.W. (2000) A General Methodology for Bootstrapping in Non-Parametric Frontier Models. Journal of Applied Statistics, 27, 779-802. https://doi.org/10.1080/02664760050081951

[38] Hammonds, J.S., Hoffman, F.O. and Bartell, S.M. (1994) An Introductory Guide to Uncertainty Analysis in Environmental and Health Risk Assessment. Environmental Restoration Program. US Department of Energy, Oak Ridge.

[39] (2009) Crystal Ball User’s Guide, 11.1.1.3.00. Fusion, Redwood City. 